\title{
Effect of Polyvinyl Alcohol Content and After Synthesis Neutralization on Structure, Mechanical Properties and Cytotoxicity of Sol-Gel Derived Hybrid Foams
}

\author{
Agda Aline Rocha de Oliveira ${ }^{\mathrm{a} *}$, Viviane Silva Gomide ${ }^{\mathrm{a}}$,Maria de Fátima Leite ${ }^{\mathrm{b}}$, \\ Herman Sander Mansur ${ }^{\mathrm{a}}$, Marivalda de Magalhães Pereira ${ }^{\text {a* }}$

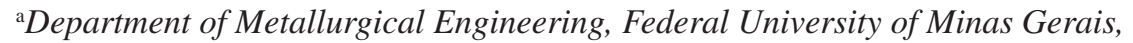 \\ Belo Horizonte - MG, Brazil \\ ${ }^{\mathrm{b}}$ Department of Biology, Federal University of Minas Gerais, Belo Horizonte - MG, Brazil
}

Received: August 20, 2008; Revised: April 16, 2009

\begin{abstract}
Bioactive glass/polymer hybrids are promising materials for biomedical applications because they combine the bioactivity of these glasses with the flexibility of polymers. In this work it was evaluated the effect of increasing the PVA content of the on structural characteristics and mechanical properties of hybrid. The hybrids were prepared with 70 wt. (\%) $\mathrm{SiO}_{2}-30 \mathrm{wt}$. (\%) $\mathrm{CaO}$ and PVA fractions of 20 to $60 \mathrm{wt}$. (\%) by the sol-gel method. The structural and mechanical characterization was done by FTIR, SEM and compression tests. To reduce the acidic character of the hybrids due to the catalysts added, different neutralization solutions were tested. The calcium acetate alcoholic solution was the best neutralizing method, resulting in foams with final $\mathrm{pH}$ of about 7.0 and small sample contraction. The foams presented porosity of 60-85 wt. (\%) and pore diameters of 100-500 $\mu \mathrm{m}$ with interconnected structure. An increase of PVA fraction in the hybrids improved their mechanical properties. The scaffolds produced provided a good environment for the adhesion and proliferation of osteoblasts.
\end{abstract}

Keywords: hybrids, bioactive glass, polymer, compression test, biological tests

\section{Introduction}

Tissue engineering consists in the use of biomaterials to give support to cells cultured and implanted to restore, maintain, or improve tissue function ${ }^{1}$. In bone tissue engineering, scaffolds used as matrices for tissue formation plays a pivotal role, and has to fulfill a few basic requirements, that is, high porosity and proper pore size (minimum of $100 \mu \mathrm{m}$ required surface properties permitting cell adhesion, differentiation and proliferation, desirable mechanical integrity to maintain the pre-designed tissue structure, non-cytotoxicity and osteoconductivity ${ }^{2}$. The selection of the most appropriate material to produce a scaffold to be used in bone tissue engineering application is a important step towards the construction of a tissue-engineered product, since its properties will determine the properties of the scaffold ${ }^{3}$.

Bioactive glasses have good biological characteristics that indicate it as a promising matrix for bone tissue engineering. When implanted in the body, they induce an interfacial bioactive response ${ }^{4}$. Furthermore, the dissolution products of bioactive glass exert control over genetic factors of bone growth ${ }^{5}$. In previous works we developed a process that allows the production of bioactive porous foams using the sol-gel method ${ }^{6}$. These structures have appropriate porosity and interconnectivity, but have low mechanical strength and toughness, which limits its application in tissue engineering.

An approach to improve the mechanical properties of bioactive glasses is the production of organic-inorganic hybrids, where an inorganic phase, with nanodimensions, is inserted in a polymer matrix. The addition of ceramics to polymer matrices allows the production of new materials with superior properties ${ }^{7}$. Thus, one material can combine the bioactivity of ceramics with the flexibility of polymers ${ }^{8}$. The sol-gel process is potentially useful in enabling such combination in molecular and nano scales. It allows the preparation of ceramics at temperatures compatible with the polymers' processing'.
In previous work hybrid foams with $80 \mathrm{wt}$. (\%) bioactive glass and $20 \mathrm{wt}$. (\%) polyvinyl alcohol (PVA) were prepared by the sol-gel process for application as scaffold for bone tissue engineering ${ }^{9,10}$. Hybrids produced by this route had a high acid character because of the catalysts added during the process. Consequently, an additional step of neutralization was necessary to produce biocompatible foams. The neutralizing method used was the immersion of foams in solution of the ammonium hydroxide. It changed the structure of pores of the material and decreased the amount of calcium in hybrids. After neutralizing the hybrids showed strength and deformation slightly lower than before the procedure. The change of behavior of the material is related to the change of composition and pore structure. The neutralization method should be adjusted. In this work the effect of increasing the PVA content on structural characteristics of hybrid foams produced by the sol-gel method was evaluated. As well, different methods to control the acidity of hybrids produced were evaluated by variations in the $\mathrm{pH}$ of synthesis and the use of different neutralizing solutions.

\section{Materials and Methods}

The hybrids were prepared with inorganic phase composition of 70 wt. (\%) $\mathrm{SiO}_{2}-30$ wt. (\%) $\mathrm{CaO}$ and PVA fractions of 20 to 60 wt. (\%) by the sol-gel method. The sol was prepared by acid hydrolysis of tetraethyl orthosilicate and addition of $\mathrm{CaCl}_{2}$. PVA solution (20 wt. (\%)) the surfactant sodium lauryl ether sulfate and hydrofluoric acid solution were added. The mixture was vigorously stirred to form the foam, which was then cast in a container were it gelled and was dried. Hybrid samples were immersed three times, 30 minutes each, in different neutralization solutions: aqueous and 
alcoholic ammonium hydroxide solutions and aqueous and alcoholic calcium acetate solutions. After neutralization, the hybrids were dried again at $40{ }^{\circ} \mathrm{C}$ in an air circulation oven for one week and, after, under high vacuum for 48 hours. The structural and mechanical characterization of the obtained foams was done by SEM, Archimedes Method, Helium Picnometry, FTIR, analysis and compression tests.

The morphology of the films obtained was assessed by scanning electron microscopy (SEM), (JSM 6360LV, JEOL/Noran), the microscope was coupled to a dispersive energy spectrometer (EDS). The images were obtained using an accelerating voltage of $10-15 \mathrm{kV}$. Before examination, the samples were coated with Au to make them conductive.

FTIR was used to characterize the presence of specific chemical groups in the hybrids. FTIR spectra were collected with wavenumber ranging from 4,000 to $400 \mathrm{~cm}^{-1}$ during 64 scans, with $2 \mathrm{~cm}^{-1}$ resolution (Paragon 1,000, Perkin-Elmer, USA) using the diffuse reflectance spectroscopy method (DRIFTS-FTIR). The FTIR spectra were normalized and major vibration bands were identified and associated with the main chemical groups.

The mechanical behavior of the composites was evaluated by compression tests. Specimens were evenly cut from the most homogeneous region of the foam to form blocks measuring $\mathrm{x} \mathrm{y} \mathrm{z} \mathrm{mm}$. These cubic foam samples were positioned between parallel plates using equipment EMIC DL 3,000 with a crosshead velocity of $0.5 \mathrm{~mm} / \mathrm{min}$ and a $2,000 \mathrm{~N}$ load cell. At least five samples $(\mathrm{n}=5)$ of each composite system were measured and the results averaged. The modulus (taken at the maximum modulus before the onset of yield point), yield stress (defined as the end of the linear deformation region) and the corresponding strain at yield were also recorded. The elastic modulus was calculated as the slope of the initial linear portion of the stress-strain curve. The yield strength was determined from the cross point of the two tangents on the stress-strain curve around the yield point.

The cytotoxicity of foams neutralized in alcoholic calcium acetate solutions, which showed better results, was evaluated for the hybrid containing $50 \mathrm{wt}$. (\%) PVA. Osteoblasts proliferation/viability in the presence of the material was evaluated by the MTT assay. Primary osteoblasts culture was prepared according to a procedure described in previous work ${ }^{12}$. The cells were seeded into $25 \mathrm{~mL}$ tissue culture flasks, and allowed to grow in a controlled $5 \% \mathrm{CO}_{2} 95 \%$ humidified incubator at $37^{\circ} \mathrm{C}$. For the experiments, only confluent cells from the second passage were used. For the cell culture studies hybrid foams were cut, sterilized in ethylene oxide, and soaked in culture medium for 2 hours before testing. Osteoblasts were plated and, after adhesion, the foam samples were gently deposited over the cells. The density used was $5 \times 10^{4}$ cells $/ \mathrm{mL}$. The culture medium RPMI was changed in intervals of 48 hours. After 72 hours of incubation the viability of the osteoblasts was evaluated through the MTT assay, based on the reduction of tetrazolium salt to formazan crystals by dehydrogenase present in living cells mitochondria. $200 \mu \mathrm{L}$ of culture medium was left in each well and $60 \mu \mathrm{L}$ of stock MTT solution was added ( $5 \mathrm{mg} \cdot \mathrm{mL}^{-1}$ ). Two hours later, the cell morphology was analysed by inverted optical microscopy and formazan salts were solubilized with $200 \mu \mathrm{L}$ of DS $10 \% \mathrm{HCl}$. After incubation for 18 hours in a controlled $5 \% \mathrm{CO}^{2} 95 \%$ humidified incubator at $7{ }^{\circ} \mathrm{C}$, the optical density measurement was done at $595 \mathrm{~nm}$.

\section{Results and Discussion}

The foams presented porosity of $67-89 \%$ and pore diameters of $100-500 \mu \mathrm{m}$ with interconnected structure. The pore structure varied with the polymer content in the hybrid (Figure 1). After drying these

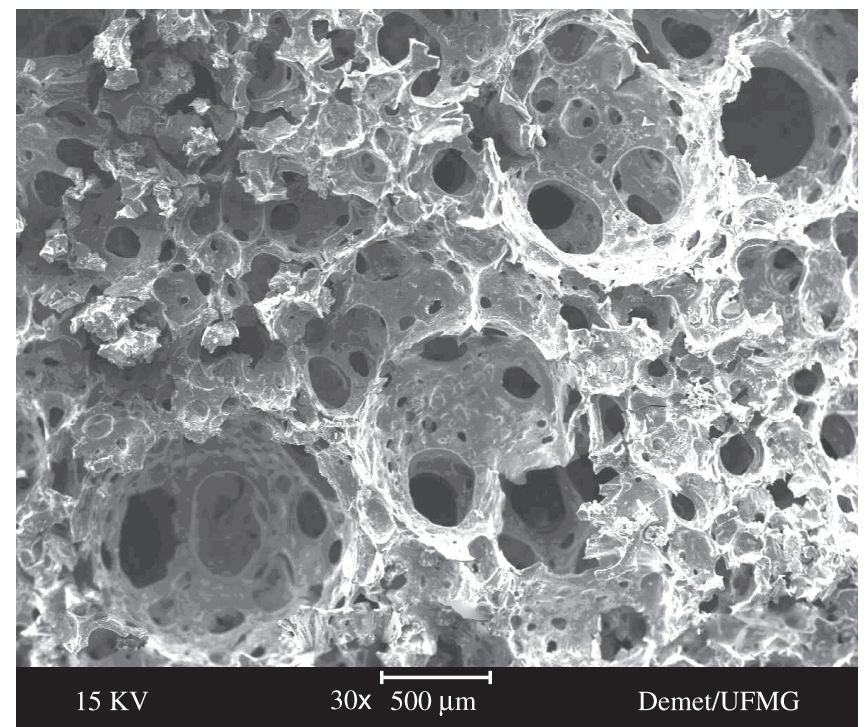

(a)

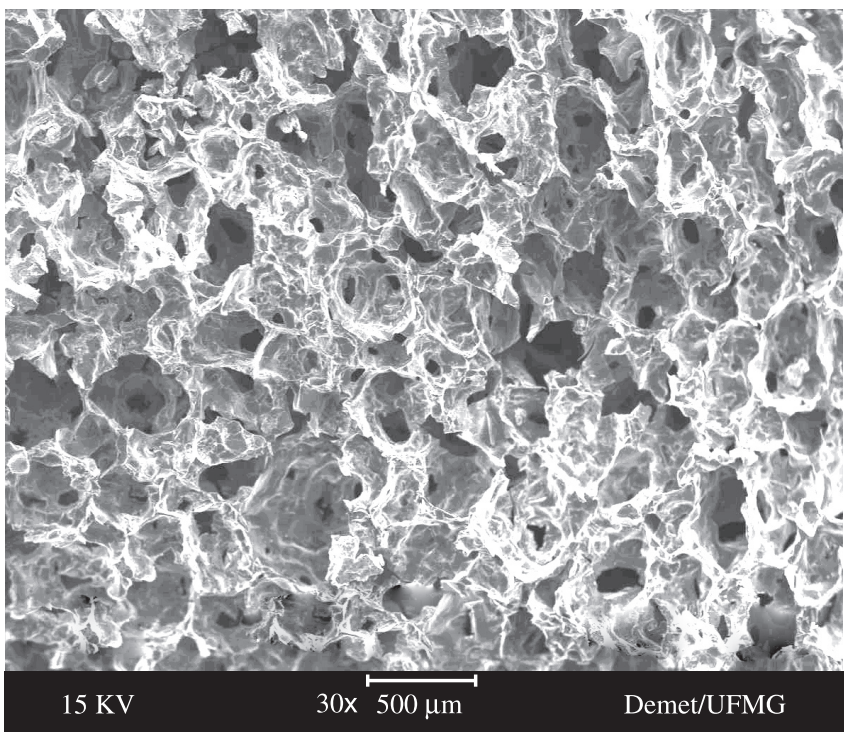

(b)

Figure 1. SEM, 30x, hybrid foams containing a) 20 and b) 60 wt. (\%) of PVA.

foams were highly acidic and the neutralization methods described previously were used to obtain samples with neutral $\mathrm{pH}$.

FTIR analysis was used to monitor the changes in the hybrid structures before and after each neutralization method. Figure 2 shows the IR spectra of the hybrid foams produced with 20 to $60 \mathrm{wt}$. (\%) of PVA, in addition to the spectra of bioactive glass and PVA. The spectra for hybrids containing 30 and $50 \%$ of PVA were omitted to improve the view of the bands in other spectra. The FTIR spectra of bioactive glass, PVA and hybrid foams (composition $20 \mathrm{wt}$. (\%) PVA) after the neutralization methods are shown in Figure 3. The analysis of silicate structures by infrared spectroscopy (FTIR) has been reported by several research groups in literature, which were used as reference ${ }^{11-39}$.

The band between 3,800 and $3,000 \mathrm{~cm}^{-1}$ was observed in all the spectra and it was assigned to stretching vibration of several hydroxyl groups. This band was composed by the overlap of the $\mathrm{SiO}-\mathrm{H}$ stretching vibration at: $3,750 \mathrm{~cm}^{-1}$, isolated $\mathrm{SiO}-H$ vicinal stretching; $3,660 \mathrm{~cm}^{-1}$, stretching of $\mathrm{H}$ connected and/or internal $\mathrm{SiO}-\mathrm{H}$ stretching; $3,450 \mathrm{~cm}^{-1}$, $\mathrm{SiO}-\mathrm{H}$ stretching in the surface silanols groups that forms Hydrogen 
Bonds with water molecules; $3,430-3,420 \mathrm{~cm}^{-1}, \mathrm{CO}-\mathrm{H}$ stretching in PVA chains and ethanol; 3,500-3,400 $\mathrm{cm}^{-1}, O-H$ stretching in water molecules. For $O-H$ stretching vibrations, there was also the band at $1,630 \mathrm{~cm}^{-1}$, assigned to deformation mode of the adsorbed water molecules.

The bands at 1,200 and $1,090 \mathrm{~cm}^{-1}$ were associated with LO and TO vibration modes, respectively, of asymmetric stretching in several cyclical species, species with 4 to $8 \mathrm{Si}$ atoms and the network. The $964 \mathrm{~cm}^{-1}$ band was assigned to $\mathrm{Si}-\mathrm{OH}$ vibration mode, attributed to the presence of $\mathrm{Ca}^{2+}$ ions. The band in the range from 830 to $760 \mathrm{~cm}^{-1}$ was the result of overlapping of the bands at $806 \mathrm{~cm}^{-1}$, related to the $\mathrm{Si}-\mathrm{O}-\mathrm{Si}$ symmetric stretching and vibration modes of rings. And the

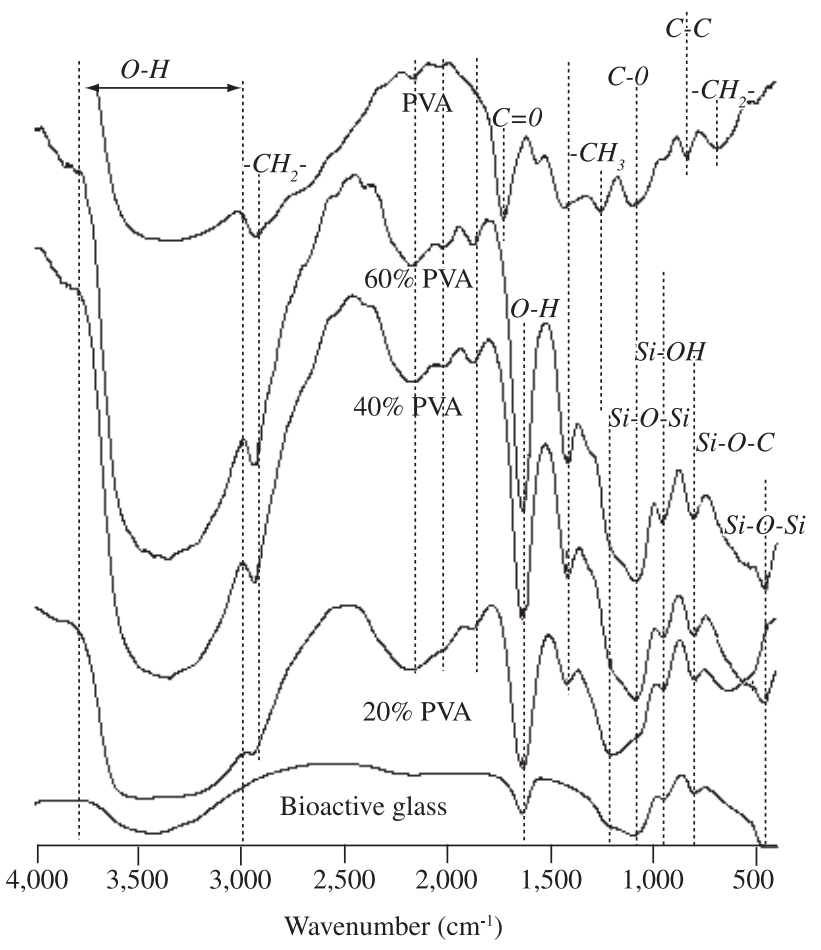

Figure 2. FTIR spectrum of bioactive glass, hybrid foams and PVA.

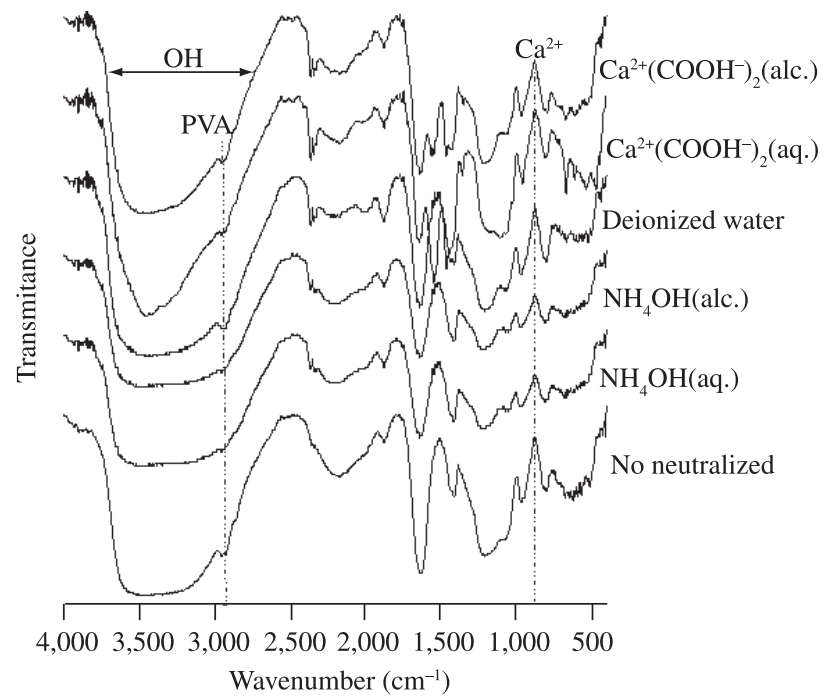

Figure 3. FTIR Spectra obtained from foams with $20 \mathrm{wt}$. (\%) of PVA, without neutralization and after the neutralization tests. band at $830 \mathrm{~cm}^{-1}$, was assigned to the $\mathrm{Si}-\mathrm{O}-\mathrm{C}$ symmetric stretching in not hydrolyzed etoxy groups that remained in hybrids. Based on the increase in the intensity of this band compared to the bioactive glass, it may indicate the formation of the $\mathrm{Si}-\mathrm{O}-\mathrm{PVA}-\mathrm{O}-\mathrm{Si}$ bond. The relative intensity of $830-760 \mathrm{~cm}^{-1}$ band was obtained after the normalization of IR spectra and subtraction of an appropriate baseline, the intensities of each hybrid was divided by the intensity of the band in the bioactive glass. The results are presented in Figure 4.

It should be pointed that the increase in the intensity of the band at 830 to $760 \mathrm{~cm}^{-1}$ was only an indicative of the incorporation of PVA in the network, considering that the increase in the $830 \mathrm{~cm}^{-1}$ band occurred because of the increase in PVA content. Moreover, it was considered that the intensity associated at $\mathrm{Si}-\mathrm{O}-\mathrm{Si}$ in the $806 \mathrm{~cm}^{-1}$ band, should not increase because of the glass fraction in the hybrid composition decreases.

The band at 2,940 $\mathrm{cm}^{-1}$, observed in hybrids and in PVA, was assigned to $\mathrm{C}-\mathrm{H}$ asymmetric stretching in $-\mathrm{CH}_{2}-$ groups. The presence of this band in hybrids comes from the PVA chains. The $1,430 \mathrm{~cm}^{-1}$ band in the PVA was associated to $C-H$ scissor deformations in $-\mathrm{CH}_{2}-$ groups. The band related to this vibration in the hybrid moved to $1,410 \mathrm{~cm}^{-1}$ because of the overlap with the $1,400 \mathrm{~cm}^{-1}$ band assigned to $\mathrm{Si}-\mathrm{O}-\mathrm{Si}$ bending mode.

For PVA, the bands at 1,740 and $1,094 \mathrm{~cm}^{-1}$ were associated to $C=O$ and $C-O$ stretching vibrations in not hydrolyzed groups. The band at $846 \mathrm{~cm}^{-1}$ was assigned to $C-C$ stretching. The band at $1,270 \mathrm{~cm}^{-1}$ was related to $H-C-H$ bending mode in $-\mathrm{CH}_{3}$ species. The band at $700 \mathrm{~cm}^{-1}$ was assigned to $H-C-C$ bending mode in $-\mathrm{CH}_{2}$ - groups.

The time necessary to complete drying of the samples after neutralization was also a parameter measured. Samples neutralized in aqueous solution and deionized water had the drying time of 1 week in oven at $40{ }^{\circ} \mathrm{C}$ with air circulation, then 48 hours under high vacuum. The samples submitted to alcoholic neutralization solutions had their drying times reduced to 2 days, in oven, then 12 hours, under high vacuum. Therefore, the use of alcoholic solutions led to lower drying times. There was no significant difference in relation to the contraction suffered by the samples during each drying process, which can be observed by SEM images of foams obtained before and after the tests, Figure 5. After neutralizing with calcium acetate solutions, the foams presented crystals observed by SEM, probably of calcium chloride as, analyzed by EDS (not shown). Taking into account $\mathrm{pH}$, composition change and sample

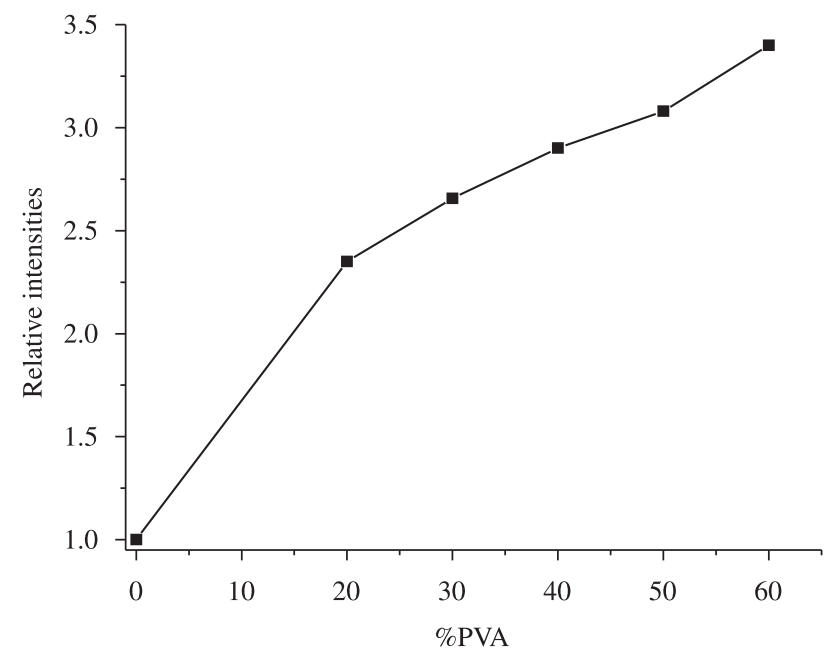

Figure 4. Relative intensities of the $830-760 \mathrm{~cm}^{-1}$ IR band of the hybrids with 20 to $60 \%$ PVA. The IR intensities for bioactive glass (0\% PVA) and PVA (100\% PVA) were showed as reference. 
contraction we conclude that immersion in calcium acetate alcoholic solution is the most adequate neutralization method.

The compression stress-strain curves for hybrid foams as prepared showed that an increase of PVA fraction in the hybrids improved their mechanical properties (Figure 6). The stress-strain curve is characterized by three regimes: at linear elastic regime, corresponding to cell edge bending or face stretching; a stress plateau, corresponding to progressive cell collapse; and densification, corresponding to collapse of the cells throughout the material ${ }^{15}$. For hybrids with lower PVA contents (20 to 30 the cell collapse is due to brittle crushing, although some plastic deformation might occur. At the final compression stage a granular material is obtained. For hybrids with higher polymer contents (40-60 wt. (\%)) the contribution of plastic yielding in the plateau increases. It can be observed an increase in compressive strength and deformation at the maximum stress with the increase in polymer content in the hybrid.

Compression stress-strain curves for foams after neutralization in calcium acetate solution are presented in Figure 7. It can be observed an increase in compressive strength and deformation at the maximum stress with the increase in polymer content in the hybrid.

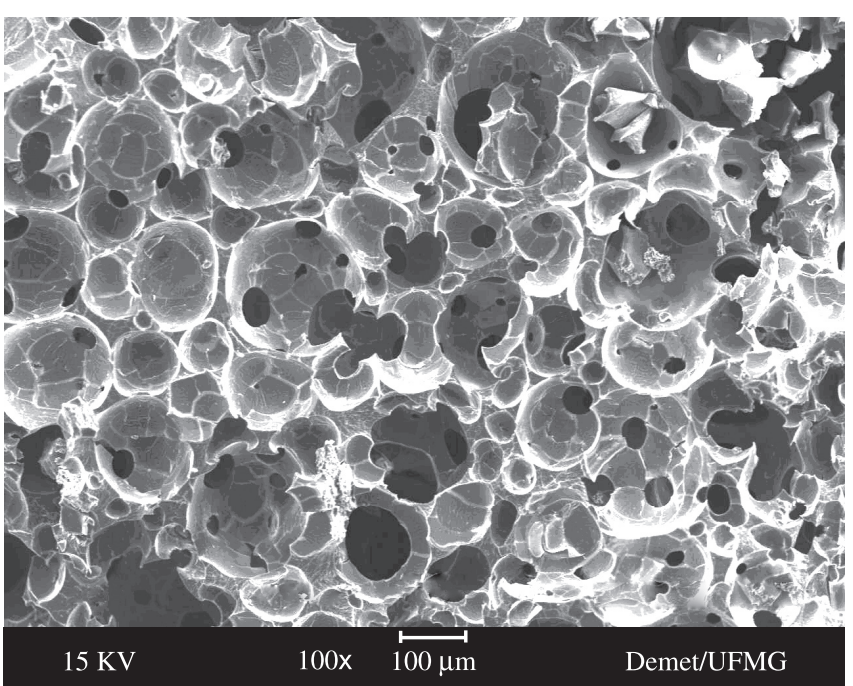

(a)

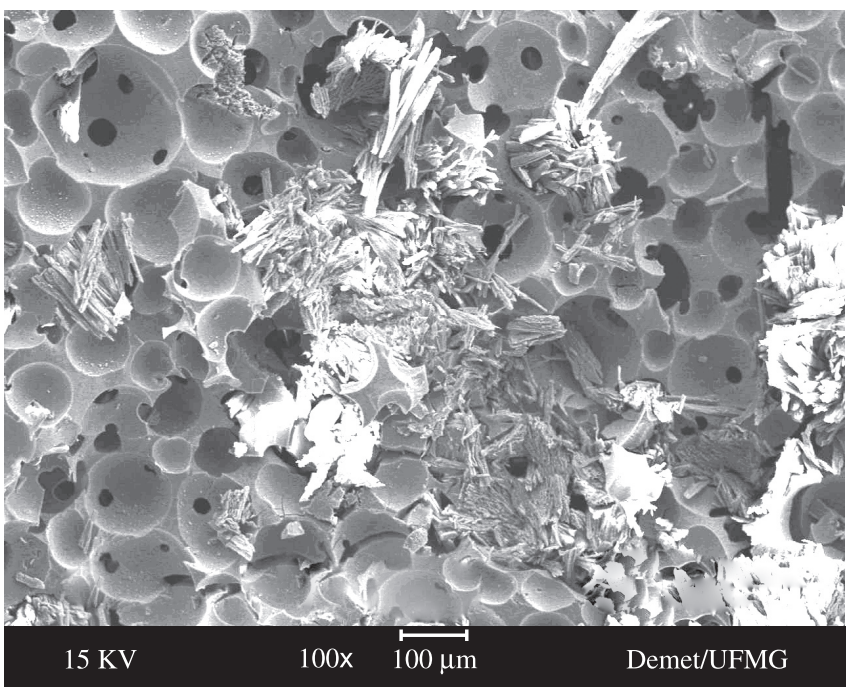

(b)

Figure 5. SEM images, increased 100x, of hybrid foams with 20 wt. (\%) PVA contend, (a) before and (b) after calcium acetate neutralization method.
The neutralization in calcium acetate solution also resulted in the improvement of the mechanical properties.

The increase in PVA content in the solution affects the foaming behavior of the mixture and therefore the final structure of the porous material obtained. It was observed a decrease in the apparent porosity as the PVA content increases, which leads to an increase in the compressive strength of the foams (Figure 7). The neutralization method also changes the final structure of the foams, as is clear by the analysis of the curves obtained before and after neutralization in Figure 8. After neutralization, the foams showed a decrease in the apparent porosity and a significant increase in the compressive strength. The apparent porosity of foams decreased between 2 to $5 \%$ after neutralization and their compressive strength increase up to $50 \%$. Based on these results, the hybrid containing $50 \mathrm{wt}$. (\%) PVA was chosen as a very promising scaffold, considering all its structural and mechanical characteristics, and therefore it was used for the biological tests.

The cellular viability studies showed that osteoblasts were viable in the culture, in the region around the hybrid foam. The optical density measurement of the solubilized formazan crystals is presented in Figure 9. It shows that osteoblast proliferation was $94 \%$ in the presence of the hybrid foam, when compared to control, or either, it did not present a statistical difference $(\mathrm{P}<0.05)$. Data were analyzed

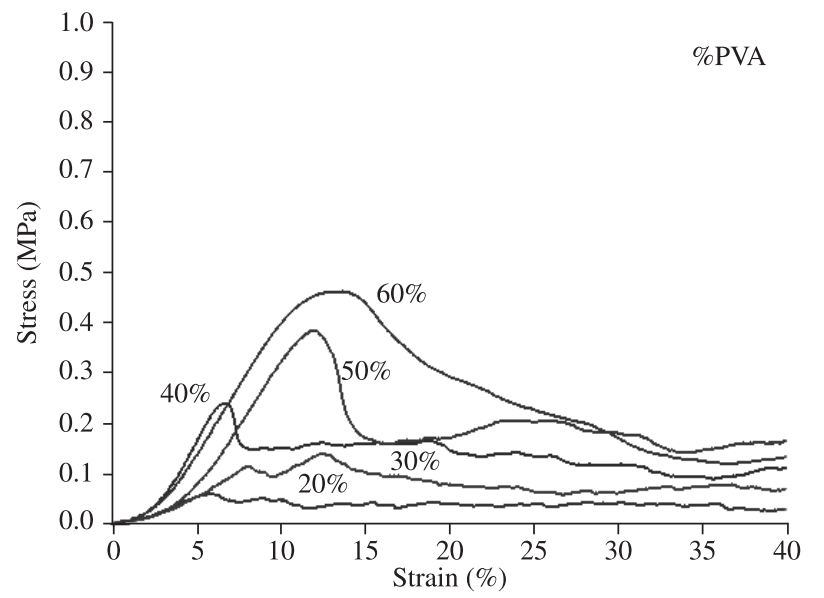

Figure 6. Compression stress-strain curves of hybrid foams with 20 to 60 wt. (\%) PVA before neutralization.

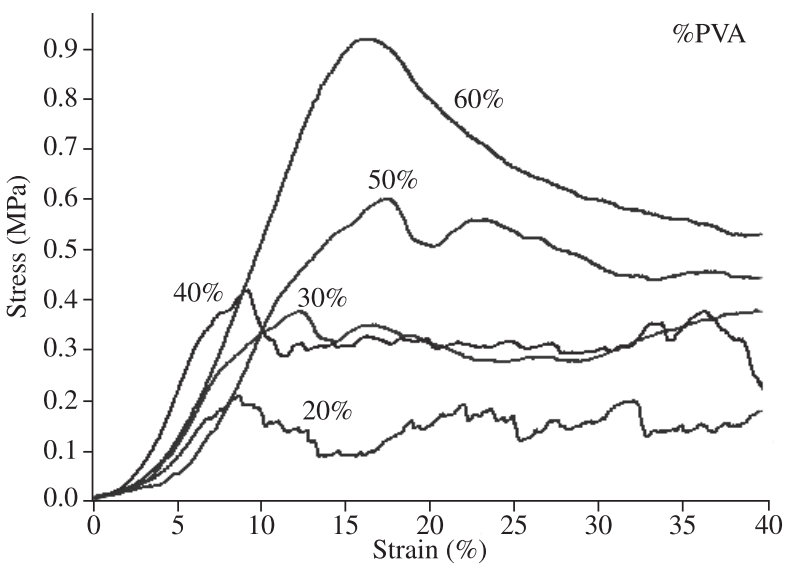

Figure 7. Compression stress-strain curves of hybrid foams with 20 to 60 wt. (\%) PVA after neutralization. 


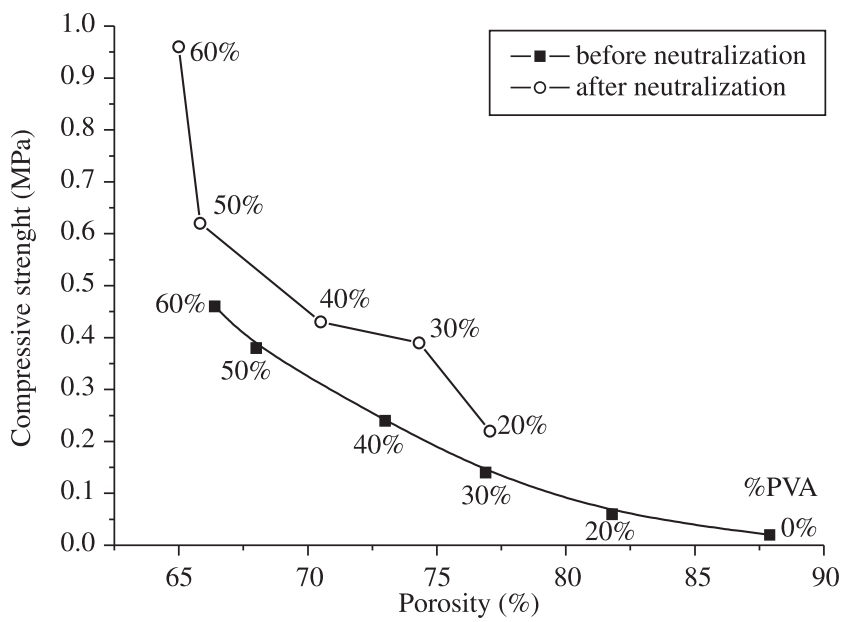

Figure 8. Compressive strength as a function of porosity and polymer content in hybrids.

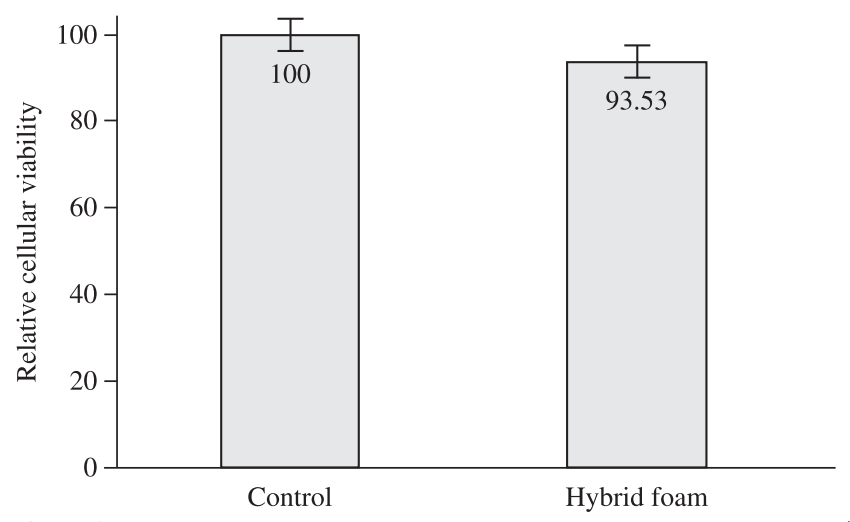

Figure 9. Osteoblast viability evaluated by MTT assay 4 days later, at $5 \times 10^{4}$ cells $/ \mathrm{mL}$ density in the presence of hybrid of the bioactive glass $50 \mathrm{wt} .(\%)$ PVA foam.

employing the GraphPad Prism signed rank test. We can conclude that osteoblast viability was not altered in the presence of the foams.

\section{Conclusions}

The hybrid foams obtained presented porosity of $67-90 \%$ and pore diameters of 100-500 $\mathrm{mm}$, porosity decreasing with polymer content up to $60 \mathrm{wt}$. (\%). The compression tests showed that an increase of PVA fraction in the hybrids improved their mechanical properties. The neutralization in calcium acetate solution led to a change in both the composition and structure of the hybrid foams, which also resulted in the improvement of the mechanical properties.

The obtained foams presented porosity of 60-85 wt. (\%) and pore diameters of $100-500 \mu \mathrm{m}$ with interconnected structure. The porosity decreased with polymer content up to $60 \mathrm{wt}$. (\%). Calcium acetate alcoholic solution was the best neutralizing method, resulting in foams with final $\mathrm{pH}$ of about 7.0 and small sample contraction. The compression tests showed that an increase of PVA fraction in the hybrids improved their mechanical properties. The apparent porosity of foams decreased between 2 to $5 \%$ and their compressive strength increase up to $50 \%$ after neutralization. The hybrid 50 wt. (\%) PVA was chosen as the best scaffold in the composition range studied and it is a promising material for bone repair.

\section{Acknowledgements}

The authors acknowledge CNPq, FAPEMIG and CAPES for financial support on this project.

\section{References}

1. Lanza PR, Langer RL, Chick W. Principles of tissue engineering. Texas: Academic Press; 1997.

2. Hench LL, Polak JM. Third-Generation Biomedical Materials. Science. 2002; 295(5557):1014.

3. Ma PX. Scaffolds for tissue fabrication. Materials Today. 2004; 7(5):30-40.

4. Hench LL, Wilson J. An Introduction to Bioceramics: advanced Series in Ceramic v.1. London: World Scientific Publushing Company, 1999.

5. Coelho MB, Pereira MM. Sol-gel synthesis of bioactive glass scaffolds for tissue engineering: effect of surfactant type and concentration. Journal of Biomedical Materials Research Part B: Applied Biomaterials. 2005; 75B(2):451-456.

6. Hokugo A, Takamoto T, Tabata Y. Preparation of Hybrid Scaffold from Fibrin and Biodegradable Polymer Fiber. Biomaterials. 2006; 27(1):61-67.

7. Vasconcelos VL, Pereira MM, Oréfice RL. Novos Biomateriais: Híbridos orgânico-inorgânicos Bioativos. Polímeros. 1999; 9(4):104-109.

8. Salinas AJ, Merino JM, Hijon N, Martin AI, Vallet-Regi M. Bioactive organic-inorganic Hybrids Based on $\mathrm{CaO}-\mathrm{SiO}_{2}$, sol-gel Glasses. Key Engineering Materials. 2004; 254-256:481-484.

9. Pereira MM, Nazhat NN, Jones JR, Hench LL. Cytotoxicity evaluation of bioactive glass-polyvinil alcohol hybrid foams prepared by the sol-gel method. Key Engineering Materials. 2005; 589(92):284.

10. Pereira MM, Jones JR, Hench LL. Bioactive glass and hybrid scaffolds prepared by sol-gel method for bone tissue engineering. Advances in applied ceramics. 2005; 35(31-34): 104.

11. Valério P, Guimarães MHR, Pereira MM, Leite MF, Goes AM. Primary osteoblast cell response to sol-gel derived bioactive glass foams. $J M S$ : Materials in Medicine. 2005; 16(9):851-856.

12. Brinker CJ, Scherer GW. Sol-Gel Science: The Physics and Chemistry of Sol-Gel Processing. London: Academic Press, Inc.; 1990.

13. Innocenzi P. Infrared spectroscopy of sol-gel derived silica-based films: a spectra-microstructure overview. Journal of Non-Crystalline Solids. 2003; 316(2):309-319.

14. Kepinski L, Maczka M, Drozd M. Formation and characterization of $\mathrm{Lu}$ silicate nanoparticles in amorphous $\mathrm{SiO}_{2}$. Journal of Alloys and Compounds. 2006; 443(1-2):132-142.

15. Mendes LS, Oliveira FC, Suarez PA, Ribim JC. Determination of ethanol in fuel ethanol and beverages by Fourier transform (FT)-near infrared and FTRaman spectrometries. Analytical Chimica Acta. 2003; 493(2):219-231.

16. Panitz J, Wokaun A. Characterization of thr sol-gel process using Raman spectroscopy organically modified silica gels prepared via the formic acid-alkoxide route. Journal of sol-gel science and technology, 1997; 9(3):251-263.

17. Ruiz F, Martínez J, Hernández G. A simple model to analyze vibrationally decoupled modes on $\mathrm{SiO}_{2}$ glasses. Journal of Molecular Structure. 2002; 641(2-3):243-250.

18. Sassi Z, Bureau J. Structural characterization of the organic/inorganic networks in the hybrid material (TMOS-TMSM-MMA). Vibrational Spectroscopy. 2002; 28(2):251-262.

19. Shimoda K, Miyamoto H, Kikuchi M, Kusaba K, Okuno M. Structural evolutions of $\mathrm{CaSiO}_{3}$ and $\mathrm{CaMgSi}_{2} \mathrm{O}_{6}$ metasilicate glasses by static compression. Chemical Geology. 2005; 222(1-2):83-93.

20. Yuan P, Wu D, He H, Lin Z. The hydroxyl species and acid sites on diatomite surface: a combine IR and Raman study. Applied surface Science. 2004; 227(1-4):30-39

21. Cerruti M, Greenspan D, Powers K. Effect of $\mathrm{pH}$ and ionic strength on the reactivity of Bioglass 45S5. Biomaterials. 2005; 26(14):1665-1674. 
22. Gallardo J, Durán A, Martino D, Almeida RM. Structure of inorganic and hybrid $\mathrm{SiO}_{2}$ sol-gel coatings atudie by variable incidence infrared spectroscopy. Journal of Non-Crystalline Solids. 2002; 298(2-3):219-225.

23. He ZW, Liu XQ, Xu DY, Wang YY. Characterization of an ultra-low k $\mathrm{SiO}_{2}$ thin film prepared by molecular template. Physica Scripta. 2006; 73(4):384-388.

24. Hsiue GH, Kuo WJ, Huang YP, Jeng RJ. Microstructural and morphological characteristics of $\mathrm{PS}-\mathrm{SiO}_{2}$ nanocomposites. Polymers. 2000; 41(8):2813-2825.

25. Keller DE, Visser T, Soulimani F, Koningsberger DC, Weckhuysen BM. Hydration effects on the molecular structure of silica-supported vanadium oxide catalysts: a combine IR, Raman, UV-vis and EXAFS study. Vibrational Spectroscopy. 2007; 43:140-151.

26. Li S, Vecchio NE, Wang Y, McNutt C. Vibrational spectra of metals treated with allyltrimethoxysilane sol-gel and self-assembled monolayer of allytrichlorosilane. Spectrochimica Acta Part A. 2006; 67(3-4):598-603.

27. Mansur HS, Oréfice RL, Mansur AAP. Characterization of poly(vinyl alcohol)/ploy(ethylene glycol) hydrogels and PVA-derived hybrids by small-angle X-ray scattering and FTIR spectroscopy. Polymer. 2004; 45(21):7193-7202.

28. Mondrágon MA, Castaño VM, Garcia M, Téllez S. Vibrational analysis of $\mathrm{Si}\left(\mathrm{OC}_{2} \mathrm{H}_{5}\right)_{4}$ and spectroscopic studies on the formation of glasses via sílica gels. Vibrational spectroscopy. 1995; 9(3):293-304.

29. Nayar S, Sinhá A. Systematic evolution of a porous hydroxyapatitepoly(vinylalcohol)-gelatin composite. Colloids and Surface. 2004; 35(1):29-32.

30. Oki A, Qiu X, Alawode O, Foly B. Synthesis of organic-inorganic hybrid composite and its thermal conversion to porous bioative glass monolith. Materials Letters. 2006; 60(21-22):2751-2755.
31. Oubaha M, Smaïhi M, Etienne P, Coudray P, Moreau Y. Spectroscopic characterization of intrisc losses in an organic-inorganic hybrid waveguide synthesized by the sol-gel process. Journal of Non-Crystalline Solids. 2003; 318(3):305-313.

32. Peitl O, Oréfice RL, Hench LL, Brennan AB. Effect of the crystallization of bioactive glass reinforcing agents on the mechanical properties of polymer composites. Materials Science and Engineering A. 2004; 372(1-2):245-251.

33. Pereira MM, Orefice RL, Mansur HS, Lopez MTP, Turchetti-Maia RMM, Vasconcelos AC. Preparation and biocompatibility of poly (methyl methacrylate) reinforced with bioactive particles. Materials Research. 2003; 6(3):311-315.

34. Rokita M, Mozgawa W, Handke M. The influence of $\mathrm{Na}^{+}$and $\mathrm{Ca}^{2+}$ ions on the $\mathrm{SiO}_{2}-\mathrm{AlPO}_{4}$ materials structure -IR and Raman studies. Journal of Molecular Structure. 2001; 596(1-3):171-178.

35. Roma G, Limoge Y, Martin-Samos L. Aspects of point defects energetics and diffusion in $\mathrm{SiO}_{2}$ from first principles simulation. Nuclear Instruments and Methods in Physics Research B. 2006; 250(1-2):54-56.

36. Shao C, Kim H, Gong J, Lee D. A novel method for making silica nanofibres by using electrospun fiber of poly(vinyl alcohol)/silica composite as precursor. Nanotechonology. 2002; 13(5):635-637.

37. Sitarz M, Handke M, Mozgawa W. Identification of silicooxygen rings in $\mathrm{SiO}_{2}$ based on IR spectra. Spectrochimica Acta Part A. 2000; 56(9):1819-1823.

38. Xu Y, Li Z, Fan W, Wu D, Sun Y, Rong L, Dong B. Density fluctuation in silica-PVA hybrid gels determined by small-angle X-ray scattering. Applied Surface Science. 2004; 225(1-4):116-123.

39. Yan H, Zhang K, Blanford CF, Francis LF, Stein A. In vitro hydroxicarbonate apatite mineralization of $\mathrm{CaO}-\mathrm{SiO}_{2}$ sol-gel glasses with Three-Dimensionally ordered macroporous structure. Chemistry of Materials. 2001; 13(4):1374-1382. 